\title{
Avaliação por Imasem do Comprometimento Osteoarticular e de Nervos Periféricos na Hanseníase
}

\section{Imasing Methods Evaluation in Osteoarticular and Peripheral Nerves Involvement in Leprosy}

\author{
Helena Lúcia Alves Pereira ${ }^{(1)}$, Sandra Lúcia Euzébio Ribeiro ${ }^{(2)}$, Rozana Mesquita Ciconelli(i), \\ Artur da Rocha Correa Fernandes ${ }^{(4)}$
}

\begin{abstract}
RESUMO
$\mathrm{Na}$ hanseníase, lesões ósseas por invasão direta do bacilo são de baixa incidência, e os achados radiológicos destas lesões são de osteomielite aguda ou crônica similares aos de outras infecções granulomatosas. As lesões ósseas mais comuns são devidas ao trauma e a infecção secundária nos tecidos denervados. Radiograficamente, são observados vários graus de reabsorção das extremidades distais envolvendo mãos e pés, ocasionando perda dos dígitos e osteoartropatia neuropática de pequenas articulações. Os achados radiológicos são semelhantes às outras condições nas quais há déficit sensorial, como esclerodermia, siringomielia e diabetes mellitus. A ultra-sonografia (US) e a ressonância magnética (RM) podem ser úteis na avaliação do comprometimento dos nervos periféricos auxiliando no diagnóstico das neurites, abscessos e no diagnóstico diferencial das síndromes compressivas.
\end{abstract}

Palavras-chave: hanseníase, lesões ósseas, neuropatia, radiologia, US, RM.

\section{INTRODUÇÃO}

A hanseníase, cujo agente etiológico é o Mycobacterium leprae, bacilo intracelular obrigatório, é endêmica no Brasil. O número de casos registrados posiciona o país como o segundo no mundo, sendo um dos poucos na América Latina a registrar crescimento das taxas de detecção de $\operatorname{casos}^{(1)}$. No ano de 2004, dos 407 mil casos novos de hanseníase detectados no mundo, 49 mil foram identificados no Brasil ${ }^{(2)}$.

O Mycobacterium leprae possui alta infectividade e baixa patogenicidade, conseqüentemente muitos indivíduos permanecem portadores do bacilo sem desenvolver a doença. $\mathrm{O}$ bacilo tem predileção pelas células da pele $\mathrm{e}$ nervos periféricos, e o diagnóstico baseia-se no encontro de

\begin{abstract}
In leprosy, bone lesions due direct invasion of bacilli are low in incidence and these lesions exhibit radiologic findings of acute and chronic osteomyelitis similar to those of other granulomatous infectious agents. The more common bone lesions are those due to injurious effects of trauma and infection imposed upon denervated tissues. Radiographycally are seen various degrees of reabsorption of the extremities involving hands and feet with the loss of digits and disorganizing arthropathies in small joints. The radiologic appearance are similar to other conditions in which there is sensory impairment like scleroderma, syringomielia and diabetes mellitus. The ultrasonography and magnetic resonance imaging (MRI) can be helpful in evaluation of the involvement of the peripheral nerves helping in the diagnosis of the neuritis, abscess and differential diagnosis in compressive syndromes.
\end{abstract}

Keywords: leprosy, bone lesions, neuropathy, radiology, US, MRI.

lesões cutâneas típicas, espessamento de nervos periféricos e baciloscopia positiva.

A hanseníase apresenta um grande espectro de formas clínicas, as quais dependem essencialmente da resposta imune do hospedeiro ${ }^{(3)}$. De um lado do espectro, o pólo tuberculóide, relativamente benigno, com alta resistência ao bacilo, e manifestações clínicas relacionadas à exacerbação da resposta imune celular com formação de granuloma bem definido, limitação das lesões cutâneas e destruição dos bacilos. No pólo oposto, a forma virchowiana altamente susceptível ao bacilo, caracterizada por deficiência da resposta imune celular e ativação da resposta imune humoral. Clinicamente, os pacientes apresentam lesões cutâneas múltiplas e difusas

1. Médica Reumatologista Assistente do Hospital Universitário Getúlio Vargas, Universidade Federal do Amazonas (UFAM), pós-graduanda da Disciplina de Reumatologia da Universidade Federal de São Paulo (UNIFESP).

2. Professora do Departamento de Clínica Médica, Disciplina de Reumatologia da UFAM, pós-graduanda da Disciplina de Reumatologia da Universidade de São Paulo (USP).

3. Médica Assistente Doutora da Disciplina de Reumatologia do Departamento de Medicina da UNIFESP.

4. Departamento de Diagnóstico por Imagem da UNIFESP.

Endereço para correspondência: Helena Lúcia Alves Pereira, Rua Apurinã, 4, Praça 14 de Janeiro, Manaus, CEP 69020-170, AM, Brasil, telefone (92) 3239-3002. e-mail: hlucia@vivax.com.br 
ricas em bacilos e, sem tratamento, pode ocorrer disseminação da doença. Entre os dois pólos, encontram-se as formas instáveis ou borderlines que representam formas mistas de apresentação com características de ambas as formas. São denominadas borderline tuberculóide quando se aproximam do pólo tuberculóide ou borderline virchowiana quando se dirigem para o outro extremo do espectro. Esta forma apresenta lesões neurais freqüentes, algumas vezes graves ${ }^{(4)}$.

O comprometimento dos nervos periféricos ocorre através de processo inflamatório causado pela ação direta do bacilo ou por reações imunológicas do organismo à presença do bacilo, resultando em alterações sensitivas e motoras, responsáveis pelas incapacidades e deformidades físicas. $\mathrm{O}$ bacilo tem predileção para infectar regiões mais frias do corpo, conseqüentemente, as lesões são vistas nestas áreas.

O comprometimento osteoarticular na hanseníase foi descrito pelos chineses desde 600 a.C. No curso da hanseníase, classicamente, foram descritos três tipos de acometimento osteoarticulares: 1) artropatias neuropáticas ou de Charcot, 2) osteítes ou as artrites sépticas específicas pela presença do bacilo intra-articular e 3) osteítes ou artrites sépticas não-específicas, secundárias às infecções piogênicas decorrentes das ulcerações cutâneas ${ }^{(5)}$.

Além das lesões clássicas, vem sendo descrito na literatura nas últimas décadas o comprometimento articular inflamatório $^{(6)}$. O mecanismo etiopatogênico não está bem elucidado, mas acredita-se que seja um estado reativo ao bacilo ou a seus antígenos. As manifestações articulares ocorrem geralmente na vigência de estados reacionais, sobretudo na reação tipo 2 (eritema nodoso hansênico) ${ }^{(7-13)}$. Também são descritos casos de artropatia inflamatória em pacientes sem estados reacionais ${ }^{(14-18)}$. As reações ocorrem antes, durante e mesmo após o tratamento da hanseníase, quando se considera que houve a cura bacteriológica da doença. São recorrentes e, em muitos pacientes, podem durar anos. A artrite relacionada ao eritema nodoso tem início súbito, é predominantemente poliarticular, semelhante à apresentação aguda da artrite reumatóide (AR). Porém, casos de comprometimento oligo ou monoarticular também ocorrem ${ }^{(7,12)}$. Com a instituição do tratamento específico ou da reação, na maioria das vezes há remissão do quadro articular, porém, artrite flutuante e persistente pode ocorrer apesar do tratamento.

\section{DIAGNÓSTICO POR IMAGEM}

\section{ASPECTOS RADIOGRÁFICOS}

As lesões osteoarticulares atribuídas à hanseníase podem ser divididas em específicas e não-específicas ${ }^{(19)}$ (Tabela 1 ).
Outros achados incluem alterações secundárias a processo inflamatório articular e osteoporose.

\section{LESÕES ESPECÍFICAS}

Estas lesões são observadas nos pacientes com hanseníase virchowiana e sua freqüência varia de 3 a $5 \%{ }^{(20)}$. São decorrentes da invasão óssea pelo bacilo por extensão de um foco infeccioso localizado na pele ou mucosas e acomete principalmente ossos da face, mãos e pés. Inicialmente, há comprometimento do periósteo, e subseqüentemente do córtex, esponjosa e medula. As trabéculas ósseas são invadidas por tecido de granulação, contendo macrófagos com abundantes bacilos álcool-ácido resistentes. Ocorrem fragmentação, necrose e destruição gradual das trabéculas ${ }^{(21)}$.

$\mathrm{Na}$ face, o comprometimento da cartilagem nasal é uma manifestação tardia da doença. A reabsorção do septo nasal produz a típica deformidade do nariz em cela, estigma da hanseníase por séculos e atualmente manifestação rara. Quando complicado por infecção secundária pode ocorrer desintegração do septo ${ }^{(22)}$.

Nas mãos e nos pés, são observados edema fusiforme do dígito afetado, rarefação óssea, cistos únicos ou múltiplos localizados nas epífises ou diáfises, alargamento dos forames de nutrição, necrose, periostite, osteíte e osteomielite. Tardiamente, podem ocorrer fratura patológica e colapso epifisário ${ }^{(23)}$.

A periosteíte leprosa usualmente envolve as extremidades das falanges média e proximal nas mãos e nos pés, a cabeça dos metatarsos ${ }^{(24)}$.

Com o tratamento precoce, as alterações agudas desaparecem ou permanecem alterações residuais, como aumento na definição do osso envolvido, cistos com margens escleróticas. Nos casos de diagnóstico tardio, podem evoluir com comprometimento osteoarticular grave, com colapso da superfície articular e subluxações ${ }^{(24)}$.

Periostite e osteíte podem ocorrer em ossos longos como na tíbia, fibula e extremidade distal da ulna, sendo consideradas manifestações das reações agudas da hanseníase e, ao raio X, evidencia-se reação periosteal. Lesões radiologicamente semelhantes a estas também podem ser encontradas em outras doenças como sífilis e infecções secundárias.

A artrite específica pelo bacilo é rara e resulta da extensão de foco infeccioso localizado no tecido ósseo ou periarticular, ou menos comumente, por disseminação hematogênica. $\mathrm{O}$ comprometimento articular poderá causar destruição da articulação expressada por estreitamento do espaço articular ou mesmo fusão das falanges. Ocasionalmente, são detectados bacilos no líquido sinovial ${ }^{(25)}$. 


\section{LESÕES ÓSSEAS NÃO-ESPECÍFICAS}

$\mathrm{Na}$ hanseníase, são as lesões mais comuns. Ocorrem em 20 a $70 \%(20,24)$ dos pacientes e resultam do comprometimento dos nervos periféricos, com conseqüente denervação e perda da propriocepção levando à osteoartropatia neuropática. Podem ocorrer em todas as formas clínicas da hanseníase. As mãos e os pés são os locais mais freqüentemente acometidos.

Na literatura, são descritos dois tipos de juntas neuropáticas: a hipertrófica e a atrófica. A forma hipertrófica é manifestada por destruição e fragmentação, esclerose óssea e formação de osteófitos. Os osteófitos formados podem ser diferenciados da osteoartrite por surgirem precocemente. São maiores e têm conformação bem definida com margens arredondadas. Entretanto, é difícil distinguir dos casos graves de osteoartrite.

A forma atrófica é mais comumente encontrada em articulações dos membros superiores, com importante reabsorção óssea que dá a impressão de uma amputação cirúrgica. Esta forma é a mais frequentemente encontrada na hanseníase, podendo também ser vista em algumas outras doenças como na siringomielia, artrites sépticas, diabetes mellitus e esclerose sistêmica ${ }^{(26)}$.

Na hanseníase, a reabsorção óssea afila e/ou encurta as falanges, metacarpos e metatarsos. A reabsorção distal diminui o comprimento ósseo, enquanto que a reabsorção do osso trabecular, também chamada de atrofia óssea concêntrica, diminui a largura. A combinação de ambas dá ao osso uma aparência chamada licked candy stick (Figura 1) ${ }^{(19)}$.

Nas mãos, a reabsorção óssea inicia nas extremidades das falanges distais, locais mais sujeitos ao traumatismo, com

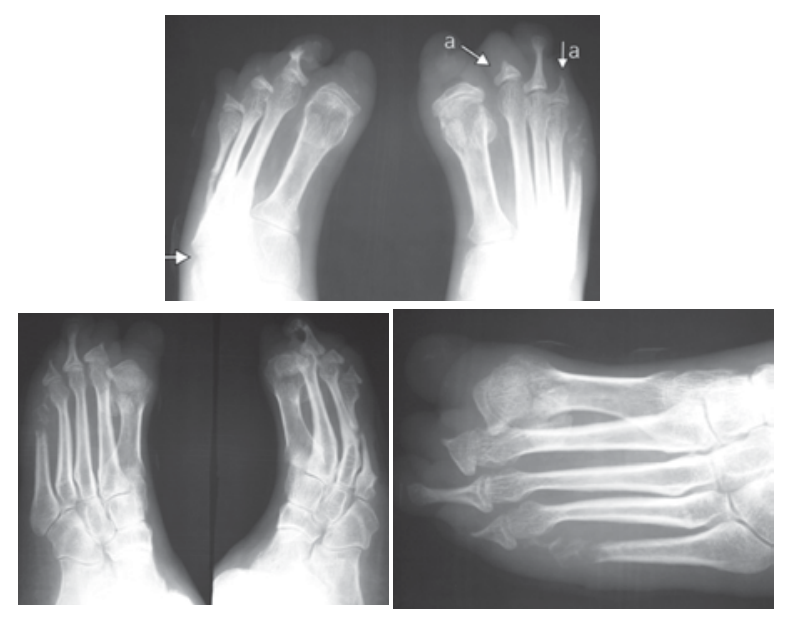

Figura 1 - Radiografia ântero-posterior dos pés, sexo masculino, forma borderline. Reabsorção das falanges distais, algumas com aspecto licked candy stick (a), osteólise do $5^{\circ}$ metatarsiano esquerdo, afilamento do $4^{\circ}$ metatarsiano direito e amputação do $5^{\circ}$. Erosão do osso cubóide (b). acometimento subseqüente das falanges médias e proximais e, mais raramente, dos ossos metacarpianos (Figura 2).

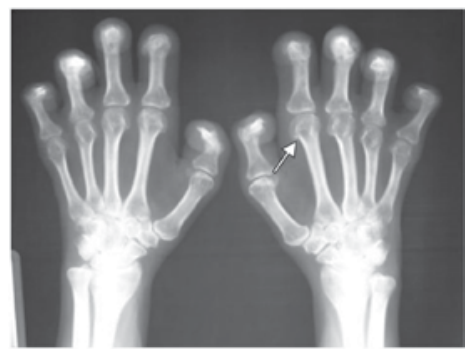

Figura 2 - Radiografia antero-posterior de mãos, sexo feminino, forma virchowiana. Atitude em hiperflexão, reabsorção das falanges distais, sinais de artropatia com redução do espaço articular e osteófitos em gota na face radial das metacarpofalangeanas, (seta) estes também encontrado nas artrites por cristais.

Na presença de infecções secundárias associadas, o processo de reabsorção progride mais rapidamente, podendo ocorrer perda dos dígitos.

Na deformidade em garra, as articulações interfalangeanas proximais em flexão ficam sujeitas ao trauma, enquanto que as extremidades distais são poupadas. As radiografias das mãos evidenciam erosões das superfícies articulares, fraturas e outras evidências de artrite destrutiva.

Nos pés, a distribuição anormal de carga na superfície plantar leva ao trauma no sítio de maior pressão, ocasionando ulcerações, reabsorção óssea ou alterações osteoartríticas secundárias. A primeira articulação metatarsofalangiana é a mais frequentemente comprometida porque é o sítio que recebe maior carga durante a marcha. A reabsorção progride no sentido horizontal, podendo acometer todas as articulações metatarsofalangianas, e no sentido longitudinal em direção aos metatarsos e falanges (Figura 3).

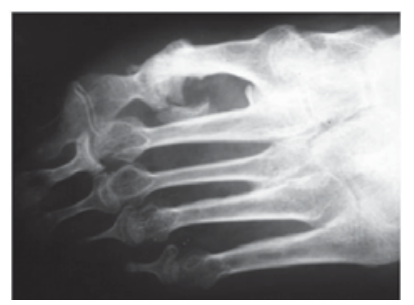

Figura 3 - Radiografia antero-posterior do pé. Reabsorção óssea no sentido longitudinal envolvendo as falanges proximais (atrofia concêntrica) e distais do $4^{\circ}$ e $5^{\circ}$ pododáctilo. Evidencia-se também reabsorção distal do $1^{\circ}$ metatarso associada a alterações osteoartríticas $2^{\mathrm{a}} \mathrm{s}$ e reação periosteal do $4^{\circ}$ e $5^{\circ}$ metatarso.

Desintegração do tarso pode envolver um ou mais ossos do tarso. As alterações afetam o arco medial, arco lateral, talo e calcâneo. Radiograficamente, são observados esclerose do osso subarticular, osteólise, fragmentação e progressiva reabsorção ${ }^{(27)}$. 
As subluxações e fraturas espontâneas são muito comuns (Figura 4), assim como as infecções secundárias como a osteomielite e artrites sépticas agudas ou crônicas, em conseqüência de ulcerações (Figura 5).

As alterações ósseas mutilantes da doença avançada são características, porém, de pouco valor diagnóstico, uma vez que as manifestações clínicas presentes não oferecem dificuldades no diagnóstico.

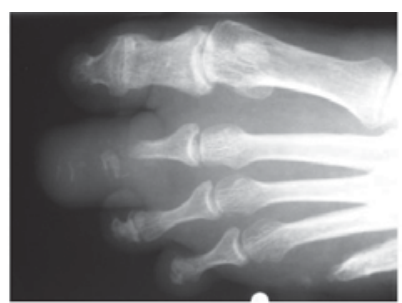

Figura 4 - Radiografia obliquo do pé, sexo masculino, forma borderline virchowiana. Fratura patológica de todos os pododáctilos.

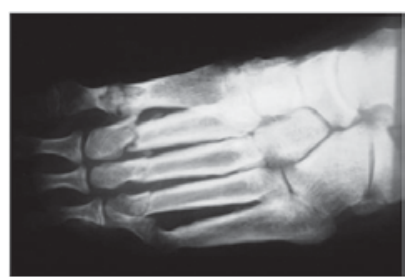

Figura 5: Radiografia ântero-posterior do pé, sexo masculino, forma virchowiana: aumento de partes moles do $2^{\circ}$ pododáctilo associado osteólise da falange distal e da articulação metatarsofalangeana caracterizando osteomielite sabaguda. Reabsorção distal do $5^{\circ}$ pododáctilo.

\section{ARTROPATIA INFLAMATÓRIA}

Nos pacientes com comprometimento articular inflamatório, as alterações radiológicas mais freqüentes são edema fusiforme de partes moles, porose justa-articular, erosões e estreitamento do espaço articular (Figura 6)(11,15,17,18). Nos casos de poliartrite, o diagnóstico diferencial com AR é mandatório. Habitualmente, as alterações radiográficas na AR são mais pronunciadas que as observadas na hanseníase.
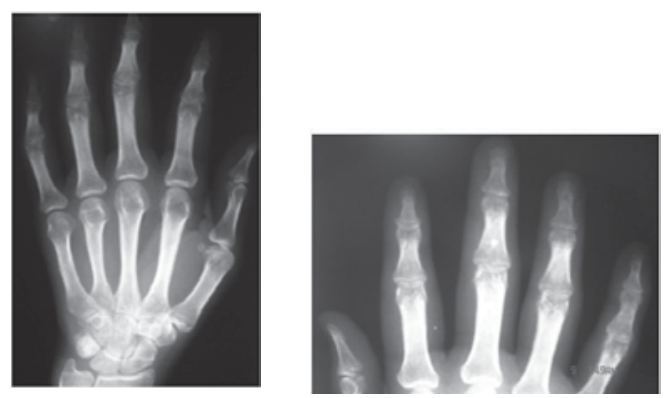

Figura 6 - Radiografia ântero-posterior de mão, sexo feminino, forma virchowiana com reação tipo 2 recorrente associada à poliartrite simétrica simulando artrite reumatóide. Observa-se aumento de partes moles e porose justa-articular.

\section{OSTEOPOROSE}

Perda de massa óssea significativa ocorre nos pacientes com hanseníase, principalmente na forma virchowiana ${ }^{(19,28)}$.
A osteoporose pode ser localizada em conseqüência da imobilização ou desuso de uma extremidade paralítica, ou difusa, decorrente da alta carga bacilar, da atrofia testicular com déficit na produção de testosterona no sexo masculino e do uso crônico de corticosteróides sistêmicos, para tratamento das reações hansênicas. Outros mecanismos etiopatogênicos provavelmente também estão implicados.

\section{ASPECTOS ULTRA-SONOGRÁFICOS}

Embora a ultra-sonografia (US) de alta resolução seja uma modalidade de imagem efetiva para mostrar alterações morfológicas dos nervos periféricos, o valor da US para o diagnóstico das doenças do sistema nervoso periférico é pouco conhecido ${ }^{(29)}$. Na hanseníase, este método também é pouco estudado para auxiliar no diagnóstico das neurites, complicações freqüentes nesta doença.

O comprometimento dos nervos periféricos na hanseníase ocorre pela invasão direta do bacilo e nos estados reacionais, especialmente na reação reversa (RR), onde o processo inflamatório intenso pode resultar em dano irreversível (Figura 7).

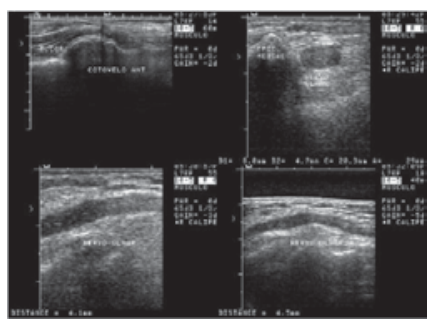

Figura 7 - Ultra-sonografia do cotovelo D, cortes longitudinal e transversal de paciente com hanseníase virchowiana tratada, com reação tipo eritema nodoso + neurite, evidenciando espessamento do nervo cubital.

Há relatos de casos na literatura em que o uso da US foi de importância para o diagnóstico de abscessos dos nervos decorrentes da infiltração pelo Mycobacterium leprae em pacientes com hanseníase, e, nestes casos, foi necessária a drenagem cirúrgica ${ }^{(30,31)}$.

Martinoli et al ${ }^{32)}$ em um estudo de 52 nervos periféricos em pacientes com hanseníase demonstrou 3 padrões à US: normal (padrão honey comb produzido pelos fascículos musculares hipoecóicos circundados pelo epineuro hiperecóico) nos pacientes que não fizeram episódios reacionais; edema fusiforme dos fascículos e alterações hipoecóicas do epineuro nos pacientes com vários episódios de reação, e, nos casos de doença de longa data, anormalidades estruturais avançadas como ausência de ecotextura fascicular e ausência de edema. Durante a fase aguda da RR, o US com Doppler mostrou um padrão hipervascular. Os auto- 
res sugerem que a realização de exame ultra-sonográfico seriado poderia ser de valor para monitorar o processo reativo durante o tratamento, especialmente nos casos em que clinicamente é impossível determinar se o paciente está em remissão ou não. A US seria útil também na seleção dos nervos mais comprometidos para os quais estaria indicada a descompressão cirúrgica ou mesmo a neurólise ${ }^{(32)}$.

Os sítios de edema no nervo são similares àqueles observados nas neuropatias compressivas (proximal ao túnel cubital, proximal ao túnel carpal e atrás do tornozelo). Entretanto, na hanseníase, o edema é fusiforme e menos circunscrito do que nas síndromes compressivas. Além disso, a US de alta resolução pode ser um bom instrumento no diagnóstico diferencial com afecções localizadas nos nervos (schwannomas, neurofibromas) ou em estruturas contíguas resultando em síndrome compressiva (ganglion, tenossinovites), especialmente nos casos em que há somente envolvimento neural (forma neurítica) sem lesões de pele, no qual o diagnóstico clinico é difícil ${ }^{(32)}$.

\section{ASPECTOS DA RESSONÂNCIA MAGNÉTICA}

A ressonância magnética ( $\mathrm{RM})$ também é um método efetivo para demonstrar aumento dos nervos, anormalidades estruturais endoneurais e sinais compressivos. Entretanto, é pouco utilizada na avaliação da hanseníase. Tem uma sensibilidade maior que a US (95\% versus 74\%) em detectar neurite por RR, porém a US é um método mais barato e acessível ${ }^{(31)}$.

$\mathrm{Na}$ seqüência ponderada em $\mathrm{Tl}$, pode ser observado decréscimo da resolução do contraste entre os fascículos e o epineuro, devido à reduzida intensidade de sinal no últi- mo. Nos pacientes com neurite em fase aguda são descritas moderada a grande intensidade de sinal em T2 e aumento do realce pós-gadolíneo (Figuras 8 e 9).

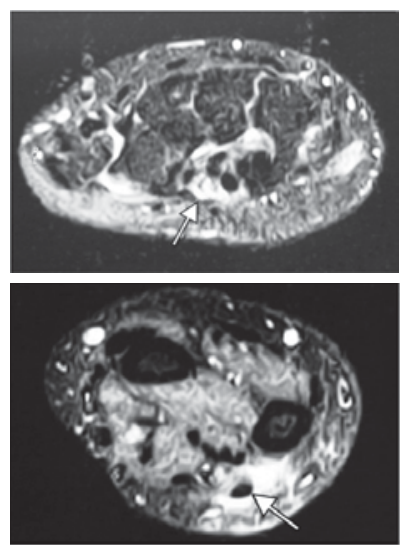

Figuras 8 e 9 - RM do mesmo paciente. Seqüência axial com supressão de gordura evidenciando realce do nervo pós-contraste.

A RM também auxilia no diagnóstico diferencial entre osteomielite e artropatia neuropática, o qual é difícil com outras técnicas de imagem.

\section{CONSIDERAÇÕES FINAIS}

O exame radiológico convencional, associado a dados clínico-epidemiológicos, permite avaliar o comprometimento osteoarticular da hanseníase.

As lesões específicas podem simular artropatias inflamatórias e as inespecíficas apresentam padrões semelhantes às neuroartropatias observadas em outras condições. Outros métodos de imagem como o US e RM podem ser empregados em situações particulares, para complementar a avaliação, colaborando para definir a melhor abordagem desses pacientes.

TABELA 1

LESÕES ÓSSEAS CLÁSSICAS DA HANSENÍASE

\begin{tabular}{c|c}
\hline Lesões específicas & Lesões não-específicas \\
\hline Aumento de partes moles & Aumento de partes moles \\
Reabsorção do septo nasal & Reabsorção falanges/metacarpos/metatarsos \\
Rarefação óssea & Mão/pé em garra \\
Cistos ósseos & Subluxações \\
Fratura patológica & Fratura patológica \\
Periostite/osteíte/osteomielite primária & Artrite séptica \\
Artrite primária & Atrofia concêntrica \\
Colapso epifisário & Desintegração tarsal \\
Alargamento dos forames de nutrição & Desorganização articular (Charcot) \\
& 0steoartrite secundária \\
\hline
\end{tabular}




\section{REFERÊNCIAS}

1. BRASIL. Ministério da Saúde. CNDS. Relatório de Atividades da Área Técnica de Dermatologia Sanitária. Brasília, 1999.

2. WHO. Report on the third meeting of the WHO Technical Advisory Group on the elimination of leprosy. Geneva, WHO: 2005, WHO/CDS/CPE/CEE/2005.

3. Ridley DS, Jopling WH: Classification of leprosy according to immunity: a five group system. Int J Lepr 34: 255-73, 1966.

4. Talhari S, Neves RG: Hansenologia, $1^{\underline{a}}$ ed, 1984.

5. Bonvoisin B, Martin JM, Bouvier M: Les manifestations articulaires de la lèpre. Sem Hôp Paris 5: 302-95, 1983.

6. Marazzi G: Reumatismo inflamatório in corso di lebbra. Reumatismo 14: 39-43, 1962.

7. Karat ABA, Karat TS, Job CK, Furness MA: Acute exsudative arthritis in leprosy-rheumatoid like syndrome in association with erythema nodosum leprosum. BMJ 3: 770-2, 1967.

8. Berman L: Exsudative arthritis in leprosy (Letter). Arthritis Rheum 20: 593, 1979

9. Albert DA, Weisman MH, Kaplan R: The rheumatic manifestations of leprosy (Hansen Disease). Medicine 59: 442-8, 1980.

10. Chavez-Legaspi M, Gómez-Vasquez A, Garcia de La Torre I: Study of rheumatic manifestations and serological abnormalities in patients with lepromatous leprosy. J Rheumatol 12: 738-741, 1985.

11. Pernambuco JAC: Artropatia inflamatória hansênica. Estudo clinico evolutivo laboratorial e radiográfico. Dissertação de Mestrado, UNIFESP,1994.

12. Lele RD, Sainani GS, Sharma KD: Leprosy presenting as rheumatoid arthritis. J Assoc Physicians India 13: 275-7, 1965.

13. Modi TH, Lele RD: Acute joint manifestations in leprosy. J Assoc Phys India 17: 247-54, 1968.

14. Alcocer JV, Herrera R, Lavalle C, Gudino J, Fraga A: Inflamatory arthropaty in Leprosy [abstract]. Arthritis Rheum 22:587, 1979.

15. Atkin SL, Welbury RR, Stanfield E, Beavis D, Iwais B, Dick WC: Clinical and Laboratory studies of inflammatory polyarthritis in patients with leprosy in Papua New Guinea. Ann Rheum Dis 46: 688-90, 1987.

16. Atkins SL, EL-Ghobarey A, Kamel M, Owen JP, Dick WC: Clinical and laboratory studies of arthritis in leprosy. BMJ 298: 1423-5, 1989.
17. Cossermelli-Messina W, Neto CF: Articular Inflamatory Manifestations in Patients with Different Forms of Leprosy. J Rheumatol 25: 111-9,1988.

18. Singh I, Kaurs S, Khandewal V: Arthritis in leprosy: Clinical, laboratory and radiological assessments. Int J Lepr Mycobact Dis 62: 428-33, 1994.

19. Enna CD: Bone Changes in Leprosy. A correlation of clinical and Radiographic Features. Radiolology 100: 295-306, 1971.

20. Paterson DE, Rad M: Bone changes in leprosy, their incidence, progress, prevention and arrest. Int J Lepr 29:393-422, 1961.

21. Job CK: Pathology of leprous osteomyelitis. Int J Lepr 31: 26$33,1963$.

22. Moller-Christensen V, Bakke SN, Melson RS, Waaler AE: Changes in anterior nasal spine and alveolar process of maxillary bone in leprosy. Int J Lepr 20: 335-40, 1952.

23. Resnick D, Niwayama G: Osteomyelitis, septic arthritis and soft tissue infection: the organisms. In: Diagnosis of Bone and Joint Disorder $2^{\text {nd }}$ ed. Philadelphia: WB Saunders 2647-2654, 1988.

24. Faget GH, Mayoral A: Bones Changes in Leprosy. A clinical and Roentgenologic Study of 505 cases. Radiology 42: 1-13, 1944.

25. Donnie JS, Koransky JR, Cohen AH: Lepra cells in synovial fluid of a patient with erythema nodosum leprosum. N Engl J Med 289: 1410-1, 1973.

26. Jones EA, Manaster BJ, May DA, Disler DG: Neuropathic osteoarthropathy: diagnostic dilemmas and differential diagnosis. Radiographics 20: S279-S293, 2000.

27. Wastic ML: Radiological changes in serial $x$-rays of the foot and tarsus in leprosy. Clin Radiol 26: 285-92, 1975.

28. Vieira, AE: Avaliação da Densidade Óssea em Pacientes com Hanseníase Dimorfa e Virchowiana. Dissertação de Mestrado UNIFESP, 1998.

29. Hong JC, Yi HC, See YC, Jin BL, Chang CY: Peripheral nerve lesions: role of high-resolution US. Radiographics 23: e15, 2003.

30. Fornage BD, Nerot C: Sonographic diagnosis of tuberculoid leprosy. J Ultrasound Med 6: 105-7, 1984.

31. Taneja K, Sethi A, Shiv VK, Khana NV, Bhargava SK: Diagnosis of nerve abscess in leprosy by sonography. Indian J Lepr 64: 105-7, 1992.

32. Martinoli C, Derchi E, Bertolotto M et al: US and RM imaging of peripheral nerves in leprosy. Skeletal Radiol 29: 142-150, 2000. 